\title{
Evaluation of indoor air quality concerns at an outpatient medical clinic in a shared-use building - West Virginia
}

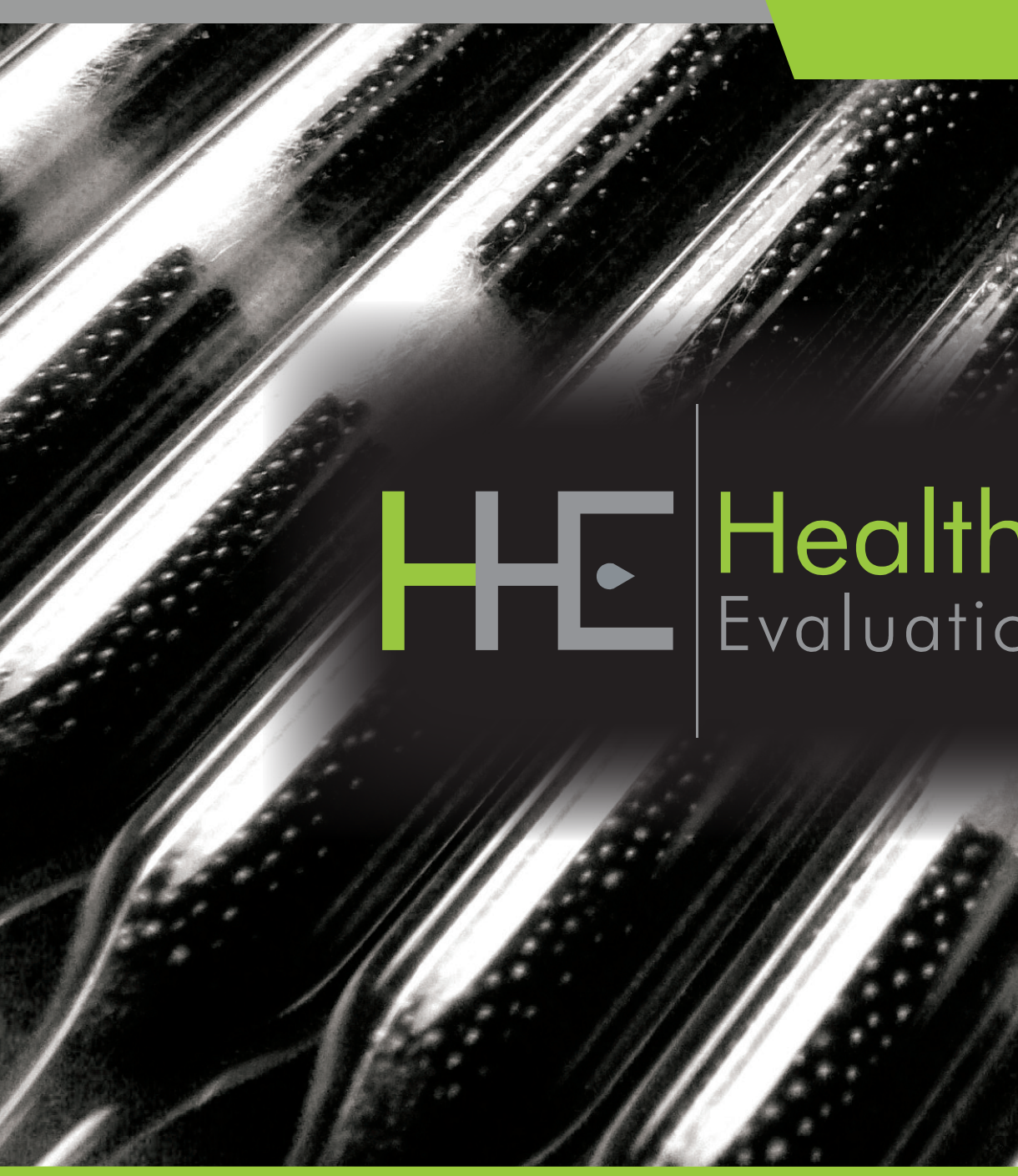

Report No. 2015-0011-3253

May 2016

Brie Hawley, PhD, MS Stephen Martin, PhD, PE Christopher Mugford, MS Randy Boylstein, MS

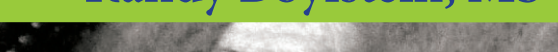




\section{Contents}

Highlights. i

Abbreviations ..............................................v

Summary.............................................. 1

Introduction ....................................... 3

Methods ................................................... 3

Results \& Discussion ........................... 5

Conclusions........................................ 13

Recommendations.......................... 14

References........................................... 16

Acknowledgements............................ 20

The employer is required to post a copy of this report for 30 days at or near the workplace(s) of affected employees. The employer must take steps to ensure that the posted report is not altered, defaced, or covered by other material.

The cover photo is a close-up image of sorbent tubes, which are used by the HHE Program to measure airborne exposures. This photo is an artistic representation that may not be related to this Health Hazard Evaluation. 


\section{Highlights of this Evaluation}

In October 2014, the National Institute for Occupational Safety and Health (NIOSH) received a health hazard evaluation request from management at an outpatient medical clinic in a shared-use building in West Virginia. The request cited concerns about indoor air quality in the building. Clinic employees reported nausea, headache, dizziness, confusion, fatigue, burning eyes, numbness of hands and fingers, tingling around lips, metallic taste, itching, and reduced work productivity. As a result of our evaluation, the medical clinic and employees have been relocated to another location offsite.

\section{What We Did}

- NIOSH investigators evaluated the facility on March 26, 2015.

- We performed real-time air sampling for carbon dioxide, carbon monoxide, temperature, and relative humidity in offices, hallways, and hallways shared with adjacent businesses.

- We collected area air samples for formaldehyde, volatile organic compounds, and isocyanates in offices, hallways, and hallways shared with adjacent businesses.

- We assessed the heating, ventilating and airconditioning systems.

- We reviewed previous indoor air assessments performed by private consultants.

- We interviewed individual employees by telephone to understand their health concerns.

\section{What We Found}

- Many employees reported respiratory and central nervous system symptoms that began on or after January 2014. Symptoms

We evaluated employee health concerns and potential worker exposure to volatile organic compounds and isocyanates. We assessed air levels of formaldehyde, volatile organic compounds, and isocyanates in the clinic and in shared hallways that surrounded the clinic. We also performed a heating, ventilation, and air-conditioning assessment. Our air samples highlighted several areas of the facility with formaldehyde air levels that approached or exceeded the NIOSH Recommended Exposure Limit. We also observed air levels within the clinic and shared hallways that suggested potential entrainment of air from neighboring businesses into the clinic. As a result of our evaluation, clinic management decided to relocate the medical clinic to another location offsite. Based on our findings, we recommend the following actions to create a more healthful workplace for future tenants. We recommend eliminating entrainment of air from neighboring businesses into the clinic, as well as follow-up air sampling to confirm this and that levels of formaldehyde in the clinic do not exceed the NIOSH Recommended Exposure Limit. reported included headache; dizziness; nausea; chest pain; amnesia; difficulty breathing; wheeze; asthma exacerbation; isolated coughing fits at work; paresthesia (a tingling or pricking feeling); metallic taste in the mouth; taste disturbances; burning eyes; and burning throat. 
- We learned that previous repairs had been performed on the heating, ventilating, and air-conditioning system to bring the clinic into positive pressure relative to adjacent businesses and to seal any visible penetrations in the firewall shared between the clinic and the neighboring businesses.

- We verified that the clinic was under positive pressure relative to the adjacent shared hallway and break room between the clinic and the wood flooring shop. We found all five of the air-handling units and associated ductwork to be clean and well-maintained. All of the systems seemed to function appropriately.

- We noted that all carbon dioxide, temperature, and relative humidity measurements were within acceptable ranges specified for indoor working environments.

- We found that no air samples had detectable levels of methylene biphenyl isocyanates, toluene diisocyanates, or hexamethylene diisocyanates.

- The highest levels of carbon monoxide were measured external to the clinic in the adjacent shared hallway/break room and in the plenum space above the adjacent shared break room, which suggests that the carbon monoxide source is external to the clinic. Levels of carbon monoxide in the clinic ranged from 1-4 parts per million. No carbon monoxide was detected outside of the building which suggests that the carbon monoxide source was not from a source outside of the building.

- We detected formaldehyde in several areas of the clinic which approached or exceeded 0.016 parts per million, the occupational exposure limit recommended by NIOSH.

- We measured levels of formaldehyde that were higher in areas adjacent to the clinic than inside of the clinic, which suggests that the source of formaldehyde is external to the clinic. However, because we were unable to view and survey the work being performed in adjacent businesses, we could not identify the source of formaldehyde.

- No detectable volatile organic compounds, other than formaldehyde, exceeded any Occupational Safety and Health Association, NIOSH, or American Conference of Governmental Industrial Hygienists exposure limits. However, we observed higher concentrations of many volatile organic compounds in shared hallways with neighboring businesses, relative to the volatile organic compound concentrations observed inside of the clinic which also suggests that the source of these volatile organic compounds is external to the clinic.

- Overall, we observed higher levels of carbon monoxide and volatile organic compounds outside of the clinic in shared hallways, which suggest the potential for entrainment of air from neighboring businesses into the clinic, despite the heating, ventilating, and airconditioning system repairs that were completed as of March 2015.

\section{What the Building Management or Future Tenant Can Do}

- Consider installing activated carbon filters in the heating, ventilating, and airconditioning systems that may lower volatile organic compound concentrations in the clinic. 
- Ensure that all plumbing, heating, ventilating, and air-conditioning system, and electrical penetrations through firewalls are sealed so the firewalls are airtight.

- Establish an anonymous environmental reporting system for staff to report buildingrelated issues.

- Building management may consider conducting air sampling in neighboring businesses to identify sources of air contaminants in the building.

- Establish a communication system with employees when building-related issues arise. Information on response actions, including exposure and environmental assessment reports, should be provided to employees.

\section{What Employees Can Do}

- Report new, persistent, or worsening symptoms to your personal healthcare provider and, as instructed by your employer, to a designated individual at your workplace.

- Report any building-related issues by using the anonymous environmental reporting system. 
This page left intentionally blank 


\section{Abbreviations}

ACGIH $^{\circledR}$

AHU

CC

CFR

EPA

${ }^{\circ} \mathrm{F}$

LOD

HVAC

$\mathrm{mL} / \mathrm{min}$

NIOSH

OSHA

PEL

PPE

ppm

ppb

REL

$\mathrm{SO}_{2}$

STEL

TLV

VOC
American Conference of Governmental Industrial Hygienists

Air-handling unit

Cubic centimeters

Code of Federal Regulations

Environmental Protection Agency

Degrees Fahrenheit

Limit of detection

Heating, ventilation, and air-conditioning

Milliliters per minute

National Institute for Occupational Safety and Health

Occupational Safety and Health Administration

Permissible exposure limit

Personal protective equipment

Parts per million

Parts per billion

Recommended exposure limit

Sulfur dioxide

Short-term exposure limit

Threshold limit value

Volatile organic compound 


\section{Summary}

NIOSH received a management request to conduct a health hazard evaluation at an outpatient medical clinic in West Virginia. The request cited concerns about indoor air quality in the building. Clinic employees reported nausea, headache, dizziness, confusion, fatigue, burning eyes, numbness of hands and fingers, tingling around lips, metallic taste, itching, and reduced work productivity.

We held voluntary confidential interviews with individual employees who wished to discuss their symptoms and concerns in October and November 2014. We learned that employees' symptoms began on or after January 2014. Additional symptoms reported by employees included chest pain, amnesia, difficulty breathing, wheeze, asthma exacerbation, isolated coughing fits at work, paresthesias (a tingling or prickling feeling), taste disturbances, and burning throat. Many employees reported that most symptoms resolved within 1-2 hours of leaving work.

We spoke with clinic health and safety management and learned that prior to this health hazard evaluation request, the clinic had been closed and employees had been relocated to another medical center on two separate occasions. In response to employee concerns, air sampling surveys were performed by health and safety consultants after the clinic first closed. The consultants sampled for volatile organic compounds (VOCs), total particulates, elements and metal compounds, carbon dioxide $\left(\mathrm{CO}_{2}\right)$, and carbon monoxide $(\mathrm{CO})$. No air levels were measured above any Occupational Safety and Health Administration (OSHA), National Institute for Occupational Safety and Health (NIOSH), or American Conference of Governmental Industrial Hygienists (ACGIH) exposure limits; however, measured levels of VOCs and $\mathrm{CO}$ suggested that air was potentially being entrained from neighboring businesses into the clinic. As a result of the air sampling surveys, consultants recommended that management (1) seal openings in the firewall to reduce and eliminate air entrainment from neighboring businesses; (2) reopen the air intake for the clinic to allow fresh, outdoor air into the clinic; and (3) modify the heating, ventilating, and air-conditioning (HVAC) systems to ensure a positive pressurization of the clinic relative to neighboring spaces. Subsequently, clinic and building management made necessary repairs to implement these recommendations. However, when employees returned to the clinic, they continued to report symptoms. The clinic was closed a second time, and employees were relocated to another medical center off-site. Consequently, additional HVAC repairs were made and the employees returned to the clinic in early 2015. Despite the repairs made, employees continued to report respiratory and central nervous system symptoms.

During an on-site assessment of the facility in March 2015, we collected area air samples in offices and in hallways shared by the clinic with neighboring businesses. We measured area air levels of formaldehyde, $\mathrm{CO}, \mathrm{CO}_{2}$, other VOCs, and isocyanates. We also performed an assessment of the HVAC systems in place.

We observed that the highest levels of CO, formaldehyde, and many other VOCs were external to the clinic in the adjacent shared hallway and break room and in the plenum space above the adjacent shared break room. Higher levels of CO, formaldehyde, and many VOCs 
in the shared hallways and plenum space suggests that the source(s) of $\mathrm{CO}$, formaldehyde, and many other VOCs were external to the clinic. No CO was detected outside of the building which suggests that the $\mathrm{CO}$ was not from a source outside of the building. Our air samples highlighted several areas of the facility with formaldehyde air levels that approached or exceeded the NIOSH recommended exposure limit (REL).

Our air sampling results indicated potential for entrainment of air from neighboring businesses into the clinic, despite the HVAC repairs made as of March 2015. As a result of our evaluation, clinic management decided to relocate the medical clinic to another location offsite. 


\section{Introduction}

The Respiratory Health Hazard Evaluation and Technical Assistance Program received a management request to conduct a health hazard evaluation at an outpatient medical clinic in West Virginia. The request cited concerns about indoor air quality in the building. Employee symptoms noted in the health hazard evaluation request included nausea, headache, dizziness, confusion, fatigue, burning eyes, numbness of hands and fingers, tingling around lips, metallic taste, itching, and reduced work production. The outpatient clinic is housed in a large multi-use building. Other businesses that are also housed in the shared building include a brewing company, a wood flooring manufacturer, a metal fabrication shop, a fluorescent light manufacturer, and a mental health clinic. As of March 2015, approximately 15 employees worked at the clinic on a daily basis. The outpatient clinic has occupied a space in this building since January 2011.

We interviewed employees who wished to discuss their symptoms and concerns by phone in October and November 2014. We learned that employee symptoms began on or after January 2014. Symptoms reported by employees included headache, dizziness, nausea, chest pain, amnesia, difficulty breathing, wheeze, asthma exacerbation, isolated coughing fits at work, paresthesias (a tingling or pricking feeling), metallic taste in the mouth, taste disturbances, burning eyes, and burning throat. Many employees reported that most symptoms resolved within 1-2 hours of leaving work. Many employees also noted that symptoms worsened later in the workday and/or later in the work week. Employees noted various odors on days that they had experienced symptoms. Specific odors reported by employees included: paint thinner, burning oil smell, polyurethane, and a non-specific chemical smell.

NIOSH visited the facility on March 26, 2015. During our visit, we collected area air samples for formaldehyde, other VOCs, and isocyanates from multiple locations within the clinic and in shared spaces adjacent to the clinic. Real-time monitoring devices were used to assess levels of $\mathrm{CO}_{2}, \mathrm{CO}$, temperature $\left({ }^{\circ} \mathrm{F}\right)$ and relative humidity within the clinic and shared spaces adjacent to the clinic. We also performed an assessment of the clinic's HVAC system. We shared our air sampling results as well as interim recommendations in two previous interim reports in April and August 2014. We understand that as a result of our evaluation and ongoing symptoms experienced by employees, that clinic management decided to permanently relocate employees to another location offsite. In this report, we summarize the results from our air sampling and HVAC assessment in March 2015. We also provide additional recommendations to help protect the health of future tenants.

\section{Methods}

\section{Informal Employee Interviews}

We asked that management inform clinic employees that they could schedule a phone call with the NIOSH Project Officer. Eight of the 15 clinic employees were interviewed. Employees shared their health concerns and were asked open-ended questions about symptom onset and 
duration, as well as any smells that were present at the onset of their symptoms.

Formaldehyde Area Air Sampling

Silica gel tubes coated with 2,4-dinitrophenylhydrazine were used to collect area air samples for formaldehyde. Air samples were collected using a pump operated at $50 \mathrm{~mL} / \mathrm{min}$. Samples were collected and analyzed according to NIOSH Method 2016 [NIOSH 2003]. Air samples were collected between 10:30 A.M. and 6:00 P.M., with total sample collection time ranging from 5-7 hours. Area air samples were collected in the following locations: (1) midway down the hallway by the clinic's mental health offices; (2) Mental Health Provider Office \#17; (3) hallway shared by the outpatient clinic and the neighboring health clinic; (4) Exam Room \#6; (5) RN Room \#41; (6) open plenum space above the clinic hallway, near Mental Health Provider Office \#17; (7) Exercise Room; (8) Exam Room \#3; and (9) the hallway shared with the wood flooring manufacturer.

\section{Volatile Organic Compound Air Sampling}

We used thermal desorption tubes to collect area air samples for VOCs. Samples were collected according to NIOSH Method 2549 [NIOSH 1996] and analyzed for VOC content according to U.S. Environmental Protection Agency (EPA) analytical method TO-17 [EPA 1999]. Air samples were collected using a pump operated at $25 \mathrm{~mL} / \mathrm{min}$. Area air samples were collected in the following locations: (1) hallway shared by the outpatient clinic and the neighboring health clinic; (2) hallway shared with the wood flooring manufacturer; (3) open plenum space above the clinic hallway, near Mental Health Provider Office \#17; (4) Mental Health Provider Office \#17; (5) RN Room \#41; and (6) Exercise Room.

Isocyanates Air Sampling

We used ASSET ${ }^{\mathrm{TM}}$ EZ4-NCO samplers to collect area air samples for isocyanates. Samples were analyzed according to International Organization for Standardization (ISO) analytical method 17734 [ISO 2013]. Air samples were collected using a pump operated at 200 ( $\mathrm{mL} / \mathrm{min})$. Area air samples were collected in the following locations: (1) midway down the mental health offices' hallway; (2) Mental Health Provider Office \#17; (3) hallway shared by the outpatient clinic and the neighboring health clinic; (4) Exam Room \#6; (5) RN Room \#41; (6) open plenum space above the clinic hallway, near Mental Health Provider Office \#17; (7) Exercise Room; (8) Exam Room \#3; and (9) the hallway shared with the wood flooring manufacturer.

Real-time Monitoring of Carbon Dioxide, Carbon Monoxide, Temperature, and Relative Humidity

$\mathrm{CO}_{2}, \mathrm{CO}$, temperature, and relative humidity measurements were taken using a VelociCalc Multi-Function Ventilation Meter 9555 and an Indoor Air Quality Probe 982 (TSI Inc., Shoreview, Minnesota). We recorded real-time measurements in clinic employees' offices, clinic hallways, the plenum space above the clinic, hallways shared with neighboring businesses, and outside by the parking lot entrance to the clinic.

Heating, Ventilation, and Air Conditioning System Evaluation

Since a thorough HVAC Testing and Balancing had been performed throughout the clinic by 
HVAC consultants on February 5, 2015 and February 18, 2015, we did not take a complete set of ventilation measurements onsite. However, we did visually inspect all of the air-handling units (AHUs) and associated ductwork, both in the mechanical space above the clinic and above the drop ceiling in the clinic itself. We also took a complete set of differential pressure measurements between the clinic and surrounding spaces, to compare those results to the HVAC testing and balancing report. The differential pressure measurements were taken with an Energy Conservatory (Minneapolis, Minnesota) DG-500 Pressure Gauge. Measurements were taken across all doorways into/out of the clinic space and some in surrounding areas.

\section{Results and Discussion}

\section{Informal Employee Interviews}

We spoke with 8 of the 15 clinic employees. We learned that employee symptoms began on or after January 2014. Symptoms reported by employees included headache, dizziness, nausea, chest pain, amnesia, difficulty breathing, wheeze, asthma exacerbation, isolated coughing fits at work, paresthesias (tingling or pricking sensation), metallic taste in the mouth, taste disturbances, burning eyes, and burning throat. Many employees reported that most symptoms resolved within 1-2 hours of leaving work. Many employees also noted that their symptoms typically worsened later in the workday and/or later in the work week.

\section{Formaldehyde Area Air Sampling}

Results from air sampling for formaldehyde are provided in Table 1. We have also provided the NIOSH and OSHA exposure limits, for reference. Area air levels above the NIOSH REL are in bold.

Table 1. Clinic air sampling results for formaldehyde, NIOSH survey, March 2015

\begin{tabular}{|l|c|}
\hline Location & Formaldehyde TWA (ppm) $^{*}$ \\
\hline Mental Health Hallway (midway down hall) & $\mathbf{0 . 0 1 7}$ \\
\hline Mental Health Provider Office \#17 & 0.014 \\
\hline Hallway between clinic and other health clinic & $\mathbf{0 . 0 2 2}$ \\
\hline Exam Room \#6 & - \\
\hline RN 41 & 0.011 \\
\hline Open plenum/ceiling-above hallway, next to \#17 & - \\
\hline Exercise Room & 0.007 \\
\hline Exam Room \#3 & - \\
\hline Shared hallway break room with wood flooring manufacturer & 0.023 \\
\hline OSHA PEL & 0.75 \\
\hline NIOSH REL & 0.016 \\
\hline ACGIH TLV & 0.30 \\
\hline
\end{tabular}

*Bolded text indicates exceedance of NIOSH REL. - Samples could not be analyzed due to pump failure.

We observed formaldehyde levels in several areas of the clinic approached or exceeded the NIOSH REL of 0.016 parts per million (ppm) [NIOSH 2010]. Additionally, as can be seen 
in Table 1, levels of formaldehyde were higher in hallways outside of the clinic when compared to levels observed inside of the clinic which suggests that the source of formaldehyde is external to the clinic. However, because we were unable to view and survey the work being performed in adjacent businesses, we could not identify the source of formaldehyde in the building.

In the United States, occupational exposure limits have been established by Federal and State agencies as well as professional organizations. Some occupational exposure limits are legally enforceable limits; others are recommendations. The OSHA PELs are legal limits that are enforceable in workplaces covered under the Occupational Safety and Health Act. OSHA PELs represent the legal maximum for a time-weighted average exposure over an 8-hour work shift, unless otherwise noted [OSHA 2016]. NIOSH provides RELs that are time-weighted average concentrations that should not be exceeded over a 10-hour work shift, during a 40 hour work week [NIOSH 2010]. ACGIH is a professional non-profit non-governmental scientific association that reviews existing published, peer-reviewed scientific literature and publishes guidelines known as threshold limit values (TLVs ${ }^{\bullet}$ ) [ACGIH 2015]. TLVs represent conditions that ACGIH has determined that nearly all workers may be repeatedly exposed without adverse health effects. The OSHA PEL is $0.75 \mathrm{ppm}$ and the ACGIH TLV is $0.30 \mathrm{ppm}$ for formaldehyde.

\section{Volatile Organic Compound Air Sampling}

Results from air samples collected and analyzed using thermal desorption tubes and EPA Analytical Method TO-17 [EPA 1999] are provided in Table 2. In the table, we provide occupational exposure limits from OSHA, NIOSH, and ACGIH for various VOCs.

No air samples for VOCs exceeded any of the OSHA, NIOSH, or ACGIH exposure limits. However, many of the VOCs in Table 2 affect similar organ systems and may have additive or synergistic effects. Where appropriate, we note the biological basis for each TLV provided in 


\begin{tabular}{|c|c|c|c|c|c|c|c|c|}
\hline 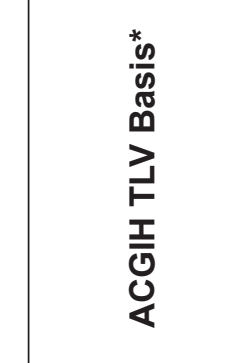 & 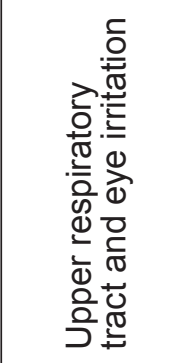 & 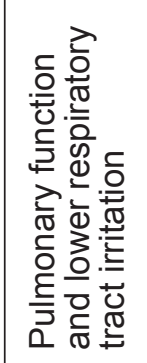 & & & 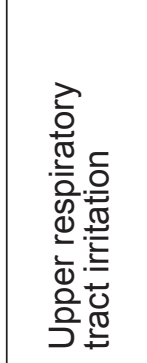 & 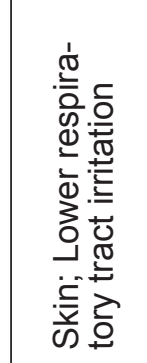 & 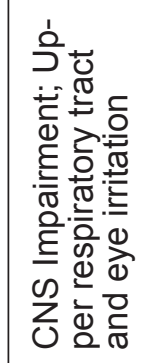 & 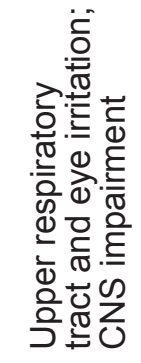 \\
\hline 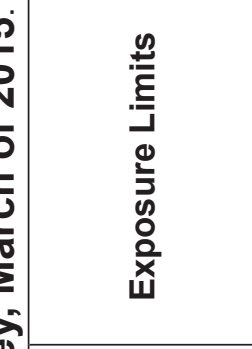 & 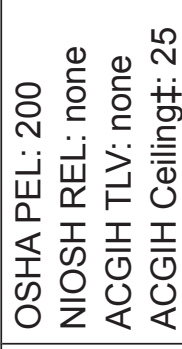 & 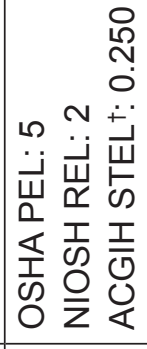 & 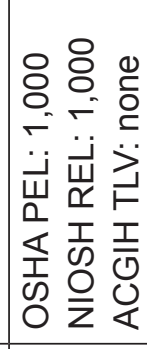 & 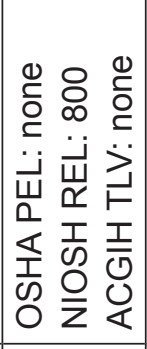 & 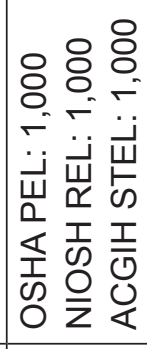 & 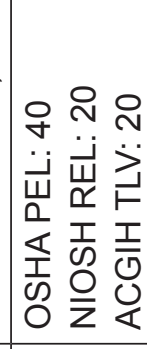 & 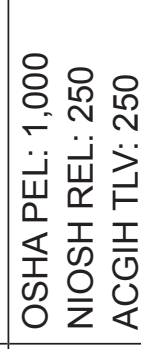 & 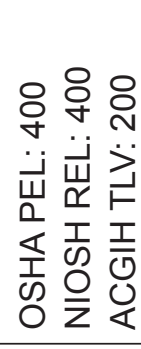 \\
\hline 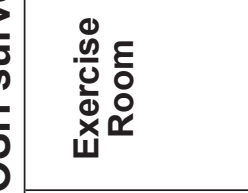 & $\begin{array}{l}\overline{5} \\
8 \\
\circ \\
0\end{array}$ & 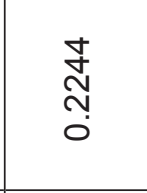 & 1 & 1 & $\begin{array}{l}\stackrel{\Omega}{\rho} \\
\stackrel{0}{0} \\
\stackrel{0}{0}\end{array}$ & 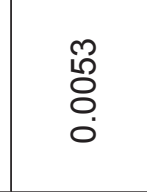 & 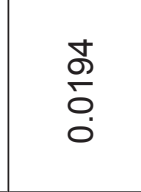 & $\begin{array}{l}0 \\
0 \\
0 \\
0 \\
0 \\
0\end{array}$ \\
\hline $\begin{array}{l}\bar{q} \\
\text { Z } \\
z\end{array}$ & 1 & 1 & 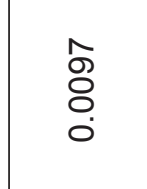 & 1 & $\begin{array}{l}\text { ○् } \\
\text { లె } \\
0 \\
0\end{array}$ & $\begin{array}{l}\bar{n} \\
\stackrel{5}{0} \\
0\end{array}$ & 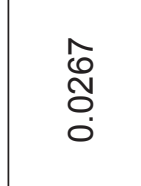 & $\begin{array}{l}\qquad \\
\stackrel{0}{0} \\
\stackrel{1}{0} \\
\stackrel{0}{\circ}\end{array}$ \\
\hline 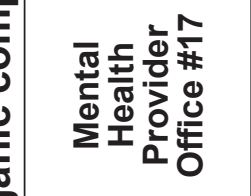 & I & I & $\begin{array}{l}\stackrel{\text { N}}{\check{0}} \\
\stackrel{\circ}{0}\end{array}$ & 1 & 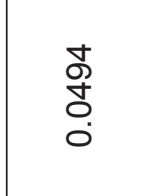 & $\begin{array}{l}\infty \\
ٌ 0 \\
0 \\
0\end{array}$ & $\begin{array}{l}\text { ठ্ } \\
\text { ర్ } \\
0\end{array}$ & $\begin{array}{l}\stackrel{8}{0} \\
\stackrel{6}{0} \\
\stackrel{0}{\circ}\end{array}$ \\
\hline 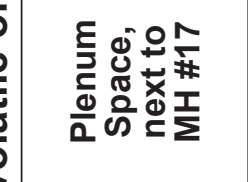 & 1 & 1 & 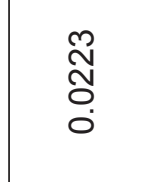 & 1 & $\begin{array}{l}\hat{\emptyset} \\
\varnothing \\
0\end{array}$ & 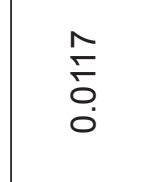 & $\begin{array}{l}\hat{0} \\
\text { مٌ } \\
0 \\
0\end{array}$ & $\begin{array}{l}\text { ָ̃ } \\
\stackrel{0}{0}\end{array}$ \\
\hline 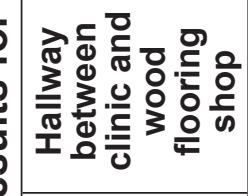 & 1 & 1 & $\begin{array}{l}\text { స్ } \\
\text { Oे } \\
0\end{array}$ & 1 & $\begin{array}{l}\text { N̂ } \\
\stackrel{1}{0} \\
\stackrel{0}{0}\end{array}$ & $\begin{array}{l}\stackrel{N}{\sigma} \\
\stackrel{0}{0}\end{array}$ & $\begin{array}{l}\hat{n} \\
\stackrel{2}{n} \\
0 \\
0\end{array}$ & 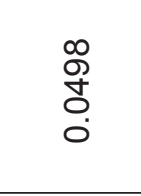 \\
\hline 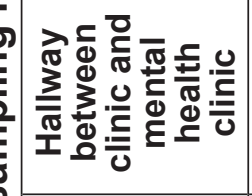 & 1 & I & $\begin{array}{l}\text { N } \\
\text { O. } \\
\text { ல }\end{array}$ & 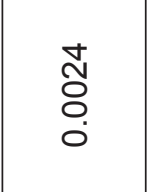 & 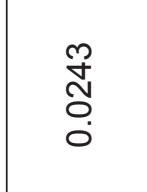 & $\begin{array}{l}\text { m} \\
\stackrel{0}{0} \\
\stackrel{0}{0}\end{array}$ & $\begin{array}{l}0 \\
1 \\
\infty \\
\circ \\
0 \\
0\end{array}$ & $\begin{array}{l}\text { ô } \\
8 \\
0 \\
0\end{array}$ \\
\hline 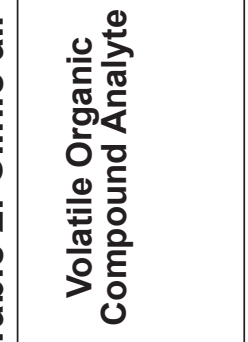 & 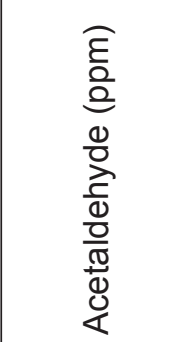 & 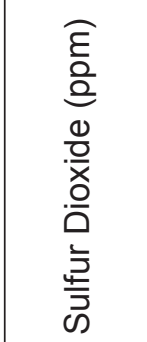 & $\begin{array}{l}\widehat{\varepsilon} \\
\overline{0} \\
0 \\
\frac{0}{\sigma} \\
\frac{0}{0} \\
\frac{0}{0} \\
\frac{0}{0}\end{array}$ & 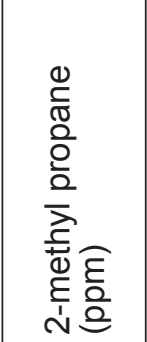 & 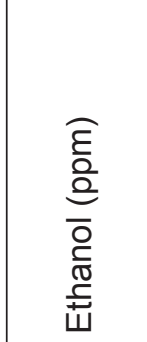 & 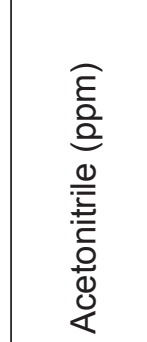 & 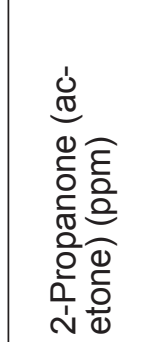 & 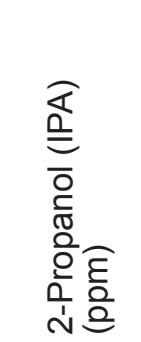 \\
\hline
\end{tabular}




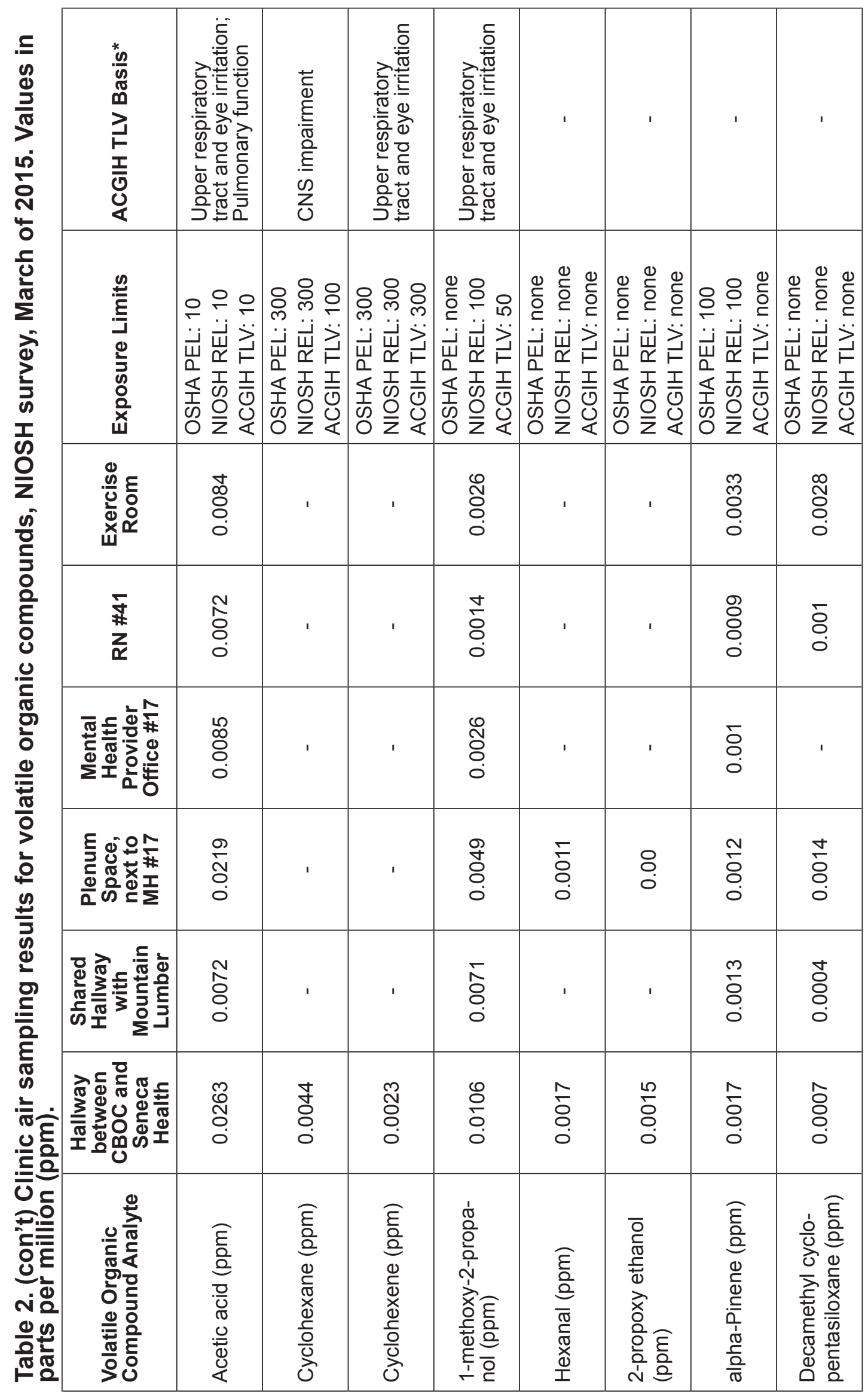




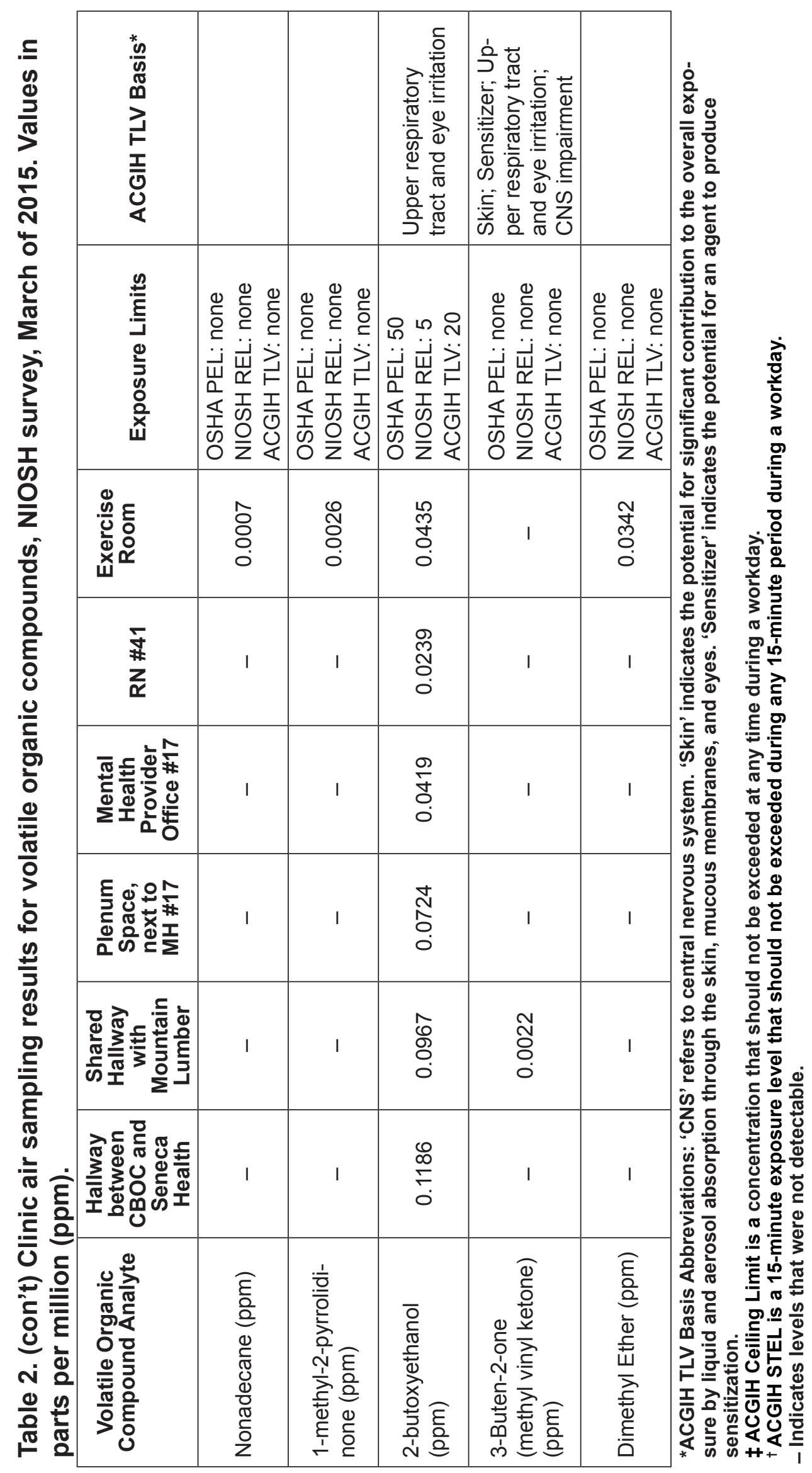


We observed higher concentrations of many VOCs in shared hallways with neighboring businesses, relative to the VOC concentrations observed inside of the clinic. Our observation of higher concentrations of propane, 2-methylpropane, acetone, cyclohexane, cyclohexene, 1-methoxy-2-propanol, 2-propoxyethanol, 2-butoxyethanol, and methyl vinyl ketone observed in shared hallways outside of the clinic suggests that the sources of these specific VOCs are external to the clinic. The VOCs observed with higher concentrations inside of the clinic, relative to levels observed in the shared hallways outside of the clinic, are commonly found in sanitizers (ethanol, isopropyl alcohol) and cosmetics such as deodorants, sunscreens or hair spray (decamethylcyclopentasiloxane).

Some VOCs were observed only in the exercise room. Because we were unable to view and survey the work being performed in adjacent businesses, we cannot explain the observation of acetaldehyde, sulfur dioxide, nonadecane, decanal, 1-methyl-2-pyrrolidinone, and dimethyl ether only in the exercise room. We could not identify any obvious source of these specific VOCs in the exercise room. Most of the VOCs observed only in the exercise room were observed at low levels ranging from 0.0007-0.0342 ppm. However, sulfur dioxide $\left(\mathrm{SO}_{2}\right)$ levels approached the ACGIH STEL of 0.250 ppm [ACGIH 2015]. An ACGIH STEL is a 15-minute exposure level that should not be exceeded during any 15-minute period during a workday. The $0.224 \mathrm{ppm} \mathrm{SO}_{2}$ concentration observed in the exercise room is notable because the EPA has established a 1-hour standard of $0.075 \mathrm{ppm}$ because of the respiratory effects associated with $\mathrm{SO}_{2}$ exposure [EPA 2011]. Although the EPA National Ambient Air Quality Standards cannot be applied directly to a workplace setting, we note that the $\mathrm{SO}_{2}$ levels measured in the exercise room exceeded the air standard that the EPA has established to protect the health and welfare of the public. $\mathrm{SO}_{2}$ in the exercise room may contribute to bronchoconstriction and increased asthma symptoms [EPA 2015]. Further, because breathing rates increase during exercise, any respiratory effects caused by $\mathrm{SO}_{2}$ exposure may be exacerbated when exercising.

\section{Isocyanates Air Sampling}

We analyzed air samples for the most commonly used isocyanates in industry and found that no air samples had detectable levels. More specifically, no air samples had detectable levels of methylene biphenyl isocyanates, toluene diisocyanates, or hexamethylene diisocyanates.

\section{Real-time Monitoring of $\mathrm{CO}_{2}, \mathrm{CO}$, temperature, and relative humidity}

We noted that all $\mathrm{CO}_{2}$, temperature, and relative humidity measurements were within acceptable ranges specified for indoor working environments [ASHRAE 2013]. ASHRAE notes in their ANSI/ASHRAE Standard 62.1-2016: Ventilation for Acceptable Indoor Air Quality that indoor $\mathrm{CO}_{2}$ concentrations no greater than $700 \mathrm{ppm}$ above outdoor $\mathrm{CO}_{2}$ concentrations will satisfy a substantial majority (about 80\%) of occupants [ANSI/ASHRAE 2016]. Since outdoor $\mathrm{CO}_{2}$ concentrations usually range between 375 to $500 \mathrm{ppm}$, indoor concentrations below 1200 ppm would be sufficient for most occupants. Additionally, assuming slow air movement (less than 40 feet per minute) and 50\% indoor relative humidity, the operative temperatures recommended by ASHRAE range from $68.5^{\circ} \mathrm{F}$ to $75^{\circ} \mathrm{F}$ in the winter, and from $75^{\circ} \mathrm{F}$ to $80.5^{\circ} \mathrm{F}$ in the summer. The difference in temperature ranges between the seasons is largely due to clothing selection. ASHRAE also recommends that indoor relative humidity be maintained at or below 
65\% [ANSI/ASHRAE 2013].

We observed CO at levels that ranged from 1-4 ppm in the clinic. We measured CO levels of approximately $4 \mathrm{ppm}$ in the plenum space above the clinic. The OSHA PEL for occupational exposure to CO is $50 \mathrm{ppm}$ [29 CFR 1910.1000], and the NIOSH REL is $35 \mathrm{ppm}$ [NIOSH 2010]. We noted that OSHA and NIOSH exposure limits are based upon a time-weighted average for an entire workday and that we only collected short-term measurements for $\mathrm{CO}$ in various locations in the clinic. Since we collected repeated measurements throughout the workday and observed levels no greater than $4 \mathrm{ppm}$ in the clinic, we believe the likelihood that CO levels in the clinic exceed the time-weighted average OSHA PEL or NIOSH REL is low. However, the OSHA and NIOSH limits are designed for occupational exposure measurements in manufacturing and other trades that have potential sources of CO (e.g., vehicle exhaust, diesel engine exhaust, welding). Typical levels of CO in offices are between 0-5 ppm [Illinois Department of Public Health 2011]. Average CO levels found in a study of six office buildings located in the United States ranged from 1-1.5 ppm [Reynolds et al. 2001]. Another study of 56 European office buildings reported average CO levels that ranged from 0.5-1.9 ppm [Bluyssen et al. 1996].

The highest levels of $\mathrm{CO}$ were measured external to the clinic in the adjacent shared hallway/ break room (6-10 ppm) and in the plenum space above the adjacent shared break room (14$17 \mathrm{ppm}$ ), which suggests that the CO source is external to the clinic. Additionally, we noted that the plenum space above the clinic and above the adjacent shared break room is separated by a drywall firewall which may not be airtight. However, we were unable to view the entirety of the firewall that separates the two plenum spaces and conduct tracer gas testing to identify potential penetrations in the firewall. No CO was detected outside of the building which suggests that the $\mathrm{CO}$ source was not from an outdoor source. We were informed by clinic staff and management that propane-powered forklifts were used in an adjacent business, and we noted that propane-powered forklifts can generate CO. However, we were unable to view all processes in operation in adjacent businesses and many combustion processes are known to generate $\mathrm{CO}$. We could not confirm that the propane-powered forklifts were the only possible source of $\mathrm{CO}$ in the building and in the clinic.

\section{Heating, Ventilation, and Air Conditioning System Evaluation}

All of the AHUs and associated ductwork appeared to be in good working order and well maintained. We did not find any supply vents disconnected from ductwork or obvious kinks in flexible duct runs. This was not surprising given the service and HVAC testing and balancing work done on the systems in the two months prior to our arrival.

The differential pressure measurements taken during the NIOSH visit are presented in Table 3. We took measurements at two different times, once when the AHU serving the break room (AHU-6) was off and again when AHU-6 was on. Our differential pressure measurements, as well as those taken by the HVAC consultants on February 18, 2015, can be seen in Table 3 . This comparison is only made to show that differential pressure differences can be significantly affected by many factors, including outside weather conditions and open doors and windows in surrounding businesses. During the NIOSH visit, it was cool, rainy, and extremely 
windy outside and the wood flooring manufacturer was operating with their large overhead garage door open. The conditions on the day of our visit may have differed from the conditions on the days when the previous HVAC consultants conducted their measurements.

Table 3. Differential pressure measurements, NIOSH survey, March 2015. Values in inches of water.

\begin{tabular}{|c|c|c|c|}
\hline Location & $\begin{array}{l}\text { HVAC Consultant } \\
\text { February } 18,2015\end{array}$ & $\begin{array}{c}\text { NIOSH } \\
\text { March 26, } 2015 \\
\text { (with AHU6 OFF) }\end{array}$ & $\begin{array}{c}\text { NIOSH } \\
\text { March 26, 2015 } \\
\text { (with AHU6 ON) }\end{array}$ \\
\hline $\begin{array}{l}\text { Main front door from outside } \\
\text { into vestibule }\end{array}$ & $\begin{array}{c}-0.0020 \\
\text { (into vestibule) }\end{array}$ & $\begin{array}{c}+0.0095 \\
\text { (out from inside) }\end{array}$ & $\begin{array}{c}0.0095 \\
\text { (out from inside) }\end{array}$ \\
\hline $\begin{array}{l}\text { Inner vestibule door to wait- } \\
\text { ing room }\end{array}$ & -0.0122 & Neutral & Neutral \\
\hline Outer door to loading dock & -0.0257 & +0.0038 & +0.0038 \\
\hline $\begin{array}{l}\text { North end of corridor be- } \\
\text { tween clinics to outside }\end{array}$ & $\begin{array}{c}-0.0220 \\
\text { (in from outside) }\end{array}$ & $\begin{array}{c}+0.0150 \\
\text { (out from inside) }\end{array}$ & $\begin{array}{c}+0.0150 \\
\text { (out from inside) }\end{array}$ \\
\hline $\begin{array}{l}\text { Northern door from corridor } \\
\text { into clinic }\end{array}$ & -0.0019 & -0.0015 & -0.0015 \\
\hline $\begin{array}{l}\text { Central door from corridor } \\
\text { into clinic }\end{array}$ & -0.0027 & +0.0010 & +0.0010 \\
\hline $\begin{array}{l}\text { West clinic door into break- } \\
\text { room (from Home-Based } \\
\text { Primary Care Offices) }\end{array}$ & Did not measure & $\begin{array}{l}+0.0010 \\
\text { (into breakroom) }\end{array}$ & +0.0045 \\
\hline $\begin{array}{l}\text { Center clinic door into break- } \\
\text { room (between Provider Of- } \\
\text { fice \#17 and Exam Room \#6) }\end{array}$ & $\begin{array}{l}+0.0035 \\
\text { (into breakroom) }\end{array}$ & $\begin{array}{l}+0.0015 \\
\text { (into breakroom) }\end{array}$ & $\begin{array}{l}+0.0050 \\
\text { (into breakroom) }\end{array}$ \\
\hline $\begin{array}{l}\text { East clinic door into break- } \\
\text { room (beside Exam Room } \\
\# 5 \text { ) }\end{array}$ & Did not measure & $\begin{array}{l}+0.0015 \\
\text { (into break room) }\end{array}$ & $\begin{array}{l}+0.0050 \\
\text { (into breakroom) }\end{array}$ \\
\hline Corridor door into breakroom & -0.0056 & Neutral & Neutral \\
\hline $\begin{array}{l}\text { Door at south end of corridor } \\
\text { to Adjacent Wood Flooring } \\
\text { Business }\end{array}$ & $\begin{array}{l}+0.0020 \\
\text { (into adjacent business) }\end{array}$ & $\begin{array}{l}-0.0080 \\
\text { (into corridor) }\end{array}$ & $\begin{array}{l}-0.0080 \\
\text { (into corridor) }\end{array}$ \\
\hline
\end{tabular}

Air flows between adjacent areas of a building are similar to air flows due to weather patterns outside; air always flows from areas of higher pressure to areas of lower pressure. When an area is under negative pressure to its surroundings, it means that air flows from the surroundings into the negative pressure space. On the other hand, an area under positive pressure pushes air out into the surroundings. The previous HVAC consultants found the clinic space under negative pressure to the surrounding areas, with the one exception where the clinic space was found to be under positive pressure to the adjacent breakroom. The long corridor between the two clinics in the building was under positive pressure to the breakroom and to the wood flooring manufacturer. Thus, air from outside the building and from the long corridor between clinics was being pulled into the clinic on February 18, 2015. Air from the corridor was being pushed into the break room and into the space occupied by the wood flooring manufacturer.

In comparison, on March 26, 2015, the clinic was mainly positive to the surrounding areas, 
which is the more preferred condition. The clinic was positive to the break room when AHU6 was off, and even more positive when AHU-6 was operational. The one exception was that the clinic was negative to the long hallway at the northern door. The long hallway was neutral (neither positive nor negative) to the break room, but slightly negative to the wood floor manufacturer at the southern door. Our observations of higher concentrations of contaminants in the hallway, relative to the clinic, may have been due to air flowing out of the wood flooring manufacturer into the corridor. Because air from the corridor was being pulled into the clinic at the northern door, and could pass across the neutral door into the breakroom, there is a potential pathway for contaminants into the open plenum space above. AHU-3, AHU-4, and AHU- 5 all share the air in the plenum space, thus, these contaminants could have been redistributed throughout the clinic space as air is recirculated. Although these pressure differentials are not conclusive proof that contaminants are entering the clinic from surrounding businesses in the same building, they do provide some evidence that a contaminant pathway is possible given certain outdoor environmental conditions and operating conditions within surrounding areas and businesses.

\section{Conclusions}

Employees reported histories of central nervous system and respiratory symptoms that began on or after January of 2014. Symptoms reported by employees included headache, dizziness, nausea, chest pain, amnesia, difficulty breathing, wheeze, asthma exacerbation, isolated coughing fits at work, paresthesias, metallic taste in the mouth, taste disturbances, burning eyes, and burning throat. Many employees also noted that their symptoms typically worsened later in the workday and/or later in the workweek and typically resolved with time away from work.

We observed formaldehyde levels in several areas of the clinic that approached or exceeded $0.016 \mathrm{ppm}$, the occupational exposure limit recommended by NIOSH [NIOSH 2010]. We note that NIOSH RELs are specified for personal air samples whereby a sample would be collected by hanging sampling equipment on the worker and collecting a sample from their breathing zone for the majority of their workday. In short, area samples cannot be used for legal enforcement. However, area samples can indicate areas with higher risks of exposure. No air samples for any of the detected VOCs exceeded any U.S. occupational exposure limits. No air samples had detectable levels of methylene biphenyl isocyanates, toluene diisocyanates, or hexamethylene diisocyanates.

We observed higher area concentrations of $\mathrm{CO}$, formaldehyde, and many VOCs in shared hallways with neighboring businesses, relative to the $\mathrm{CO}$, formaldehyde, and VOC concentrations observed inside of the clinic. Our observation of higher concentrations of CO, formaldehyde, and many VOCs observed in shared hallways outside of the clinic suggests that the sources of these gases and vapors are external to the clinic. Our air sampling results indicate the potential for entrainment of air from neighboring businesses into the clinic, despite the HVAC repairs made as of March 2015. 


\section{Recommendations}

We understand that as a result of our evaluation, clinic management decided to relocate the medical clinic to another location offsite. Based on our findings, we recommend the actions listed below to create a more healthful workplace for future tenants.

Our recommendations are based on an approach known as the hierarchy of controls. This approach groups actions by how effective they are at removing or reducing hazards. In most cases, the primary approach is to eliminate hazardous materials or processes, and to install engineering controls to reduce exposure or shield employees. Administrative measures and personal protective equipment may be needed until such engineering controls are in place, or if engineering controls are not effective or feasible.

\section{Engineering Controls}

Engineering controls can reduce employees' exposures by removing the hazard from the process or by placing a barrier between the hazard and the employee. Engineering controls protect employees effectively without placing primary responsibility of implementation on the employee.

1. Ensure that the clinic remains under positive pressure in relation to adjacent businesses. Install monitors in the walls of the clinic to monitor pressurization in the clinic.

2. Install and maintain activated carbon filters in the HVAC systems to reduce VOC concentrations in the clinic.

3. Ensure that firewalls between the clinic and adjacent businesses are as airtight as possible.

\section{Administrative Controls}

Administrative controls refer to employer-dictated work practices and policies to reduce or prevent hazardous exposures. Their effectiveness depends on employer commitment and employee acceptance. Regular monitoring and reinforcement are necessary to ensure that policies and procedures are followed consistently.

1. Establish an anonymous environmental reporting system for staff to report buildingrelated issues.

2. Building management may consider conducting air sampling in neighboring businesses to identify sources of air contaminants in the building.

3. Establish a communication system with employees when building-related issues arise. Information on response actions, including exposure and environmental assessment reports, should be provided to employees. 
4. Employees should report new, persistent, or worsening symptoms to their personal healthcare provider and, as instructed by their employer, to a designated individual at their workplace. An individualized management plan (such as assigning an affected employee to a different work location) is sometimes required, as indicated by medical findings and recommendations of the physician. Employees with symptoms should provide their personal physicians or other healthcare providers with a copy of this report. 


\section{References}

ACGIH (American Conference of Governmental Industrial Hygienist) [2015]. 2015 TLVs ${ }^{\circledast}$ and BEIs ${ }^{\oplus}$. Cincinnati, OH: ACGIH Signature Publications.

ANSI (American National Standards Institute)/ASHRAE [2013]. Thermal environmental conditions for human occupancy, standard 55-2013. Atlanta, GA: American Society of Heating, Refrigeration, and Air-Conditioning Engineers.

ANSI/ASHRAE [2016]. Ventilation for acceptable indoor air quality, standard 62.1-2016. Atlanta, GA: American Society of Heating, Refrigeration, and Air-Conditioning Engineers.

Bluyssen PM, De Oliveira Fernandes E, Groes L, Clausen G, Fanger PO, Valbjorn O, Bernhard CA, Roulet CA [1996]. European indoor air quality project in 56 office buildings. Indoor Air. 6(4):221-238.

CFR (Code of Federal Regulations). Washington, DC: U.S. Government Printing Office, Office of the Federal Register.

EPA (Environmental Protection Agency) [1999]. Compendium of methods for the determination of toxic organic compounds in ambient air: Compendium method TO-17 - Determination of volatile organic compounds in ambient air using active sampling onto sorbent tubes, Second Edition. Cincinnati, OH: Environmental Protection Agency, Center for Environmental Research Information, Office of Research and Development Available at: http://www.epa. gov/ttnamti1/files/ambient/airtox/to-17r.pdf. Date accessed: May 2016.

EPA [2011]. National ambient air quality standards (NAAQS).

Available at: https://www.epa.gov/criteria-air-pollutants/naaqs-table. Date accessed: May 2016.

EPA [2015]. Sulfur dioxide: health. Available at: http://www.epa.gov/airquality/sulfurdioxide/ health.html. Date accessed: May 2016.

Illinois Department of Public Health [2015]. Illinois department of public health guidelines for indoor air quality. Available at: http://dph.illinois.gov/topics-services/environmentalhealth-protection/toxicology/indoor-air-quality-healthy-homes/idph-guidelines-indoor-airquality. Date accessed: May 2016.

ISO (International Organization for Standardization) [2013] 17734-1: Determination of organonitrogen compounds in air using liquid chromatography and mass spectrometry - Part 1: Isocyanates using dibutylamine derivatives. Avilable at: https://www.iso.org/obp/ui/\#iso:std:iso:17734:-1:ed-2:v1:en. Date accessed May 2016.

NIOSH (National Institute for Occupational Safety and Health) [1996]. NIOSH manual of analytical methods (NMAM). 4th ed. Schlecht PC, O'Connor PF, eds. Cincinnati, OH: U.S. Department of Health and Human Services, Centers for Disease Control and Prevention, National Institute for Occupational Safety and Health, DHHS (NIOSH) Publication 94-113 
(August 1994); 1st Supplement Publication 96-135, 2nd Supplement Publication 98-119; 3rd Supplement 2003-154. Available at: http://www.cdc.gov/niosh/docs/2003-154/pdfs/2549.pdf. Date accessed: May 2016.

NIOSH [2003]. NIOSH manual of analytical methods (NMAM). 4th ed. Schlecht PC, O'Connor PF, eds. Cincinnati, OH: U.S. Department of Health and Human Services, Centers for Disease Control and Prevention, National Institute for Occupational Safety and Health, DHHS (NIOSH) Publication 94-113 (August 1994); 1st Supplement Publication 96-135, 2nd Supplement Publication 98-119; 3rd Supplement 2003-154. Available at: http://www.cdc.gov/ nioshdocs/2003-154/pdfs/2016.pdf. Date accessed: May2016.

NIOSH [2010]. NIOSH pocket guide to chemical hazards, US Department of Health and Human Services, Centers for Disease Control and Prevention, DHHS (NIOSH) Publication Number 2010-168c. Available at: http://www.cdc.gov/niosh/npg/. Date accessed: May 2016.

OSHA (Occupational Safety and Health Administration) [2016]. 29 CFR Part 1910, occupational safety and health standards, Table Z-1 limits for air contaminants. Available at: https:// www.osha.gov/pls/oshaweb/owadisp.show document?p table=STANDARDS\&p id=9992.

Date accessed: May 2016.

Reynolds SJ, Black DW, Borin SS, Breuer G, Burmeister LF, Fuortes LJ, Smith TF, Stein MA, Subramanian P, Thorne PS, Whitten P [2001]. Indoor environmental quality in six commercial office buildings in the midwest United States. Appl Occup Environ Hyg 16(11):1065-77. 
This page left intentionally blank 
Keywords: NAICS 622110 General Medical and Surgical Hospitals, respiratory, sensory, indoor air quality, IEQ, volatile organic compounds, carbon monoxide 
The Health Hazard Evaluation Program investigates possible health hazards in the workplace under the authority of the Occupational Safety and Health Act of 1970 (29 U.S.C. § 669(a) (6)). The Health Hazard Evaluation Program also provides, upon request, technical assistance to federal, state, and local agencies to invest igate occupational health hazards and to prevent occupational disease or injury. Regulations guiding the Program can be found in Title 42, Code of Federal Regulations, Part 85; Requests for Health Hazard Evaluations (42 CPR Part 85).

\section{Disclaimer}

The recommendations in this report are made on the basis of the findings at the workplace evaluated and may not be applicable to other workplaces.

Mention of any company or product in this report does not constitute endorsement by the National Institute for Occupational Safety and Health (NIOSH).

Citations to Web sites external to N1OSH do not constitute NIOSH endorsement of the sponsoring organizations or their programs or products. NIOSH is not responsible for the content of these Web sites. All Web addresses referenced in this document were accessible as of the publication date.

\section{Acknowledgments}

Desktop Publisher: Tia McClelland

NIOSH Laboratory Assistance: Ryan LeBouf

Site Visit: Brie Hawley, Steve Martin, Chris Mugford, and Randy Boylstein.

\section{Availability of Report}

Copies of this report have been sent to the employer, employees, and union at the facility. The state and local health department and the Occupational Safety and Health Administration Regional Office have also received a copy. This report is not copyrighted and may be freely reproduced.

This report is available at http://www.cdc.gov/niosh/hhe/reports/pdfs/2015-0011-.pdf.

All other HHE Reports may be found at http://www2a.cdc.gov/hhe/search.asp.

\section{Recommended citation for this report:}

$\mathrm{NIOSH}$ [2016]. Evaluation of indoor air quality concerns at an outpatient medical clinic in a shared use building - West Virginia. By Hawley B, Martin S, Mugford C, and Boylstein R. Morgantown, WV: U.S. Department of Health and Human Services, Centers for Disease Control and Prevention, National Institute for Occupational Safety and Health, NIOSH HETA No. 2015-0011$\underline{3253}$. 
Delivering on the Nation's promise:

Safety and health at work for all people through research and prevention

To receive documents or other information about occupational safety and health topics, contact NIOSH

Telephone: 1-800-CDC-INFO (1-800-232-4636)

TTY: 1-888-232-6348

email: cdcinfo@cdc.gov

or visit the NIOSH website at http://www.cdc.gov/niosh

SAFER • HEALTHIER • PEOPLE ${ }^{\text {TM }}$ 